\title{
Coulisses
}

Revue de théâtre

10 | Printemps 1994

Varia

\section{Point de vue du C.D.N.}

\section{Christine Friedel}

\section{(2) OpenEdition}

Journals

Édition électronique

URL : http://journals.openedition.org/coulisses/3706

DOI : $10.4000 /$ coulisses.3706

ISSN : 2546-9460

\section{Éditeur}

Presses universitaires de Franche-Comté

\section{Édition imprimée}

Date de publication : 1 juin 1994

Pagination : 12-13

ISSN : 1150-594X

\section{Référence électronique}

Christine Friedel, «Point de vue du C.D.N. », Coulisses [En ligne], 10 | Printemps 1994, mis en ligne le 15 mars 2019, consulté le 24 octobre 2019. URL : http://journals.openedition.org/coulisses/3706 ; DOI : 10.4000/coulisses.3706

Ce document a été généré automatiquement le 24 octobre 2019

Coulisses 


\section{Point de vue du C.D.N.}

\section{Christine Friedel}

\section{Théâtre en appartement :}

1 la formule commence à être connue. Des amateurs de théâtre invitent chez eux un public ami à partager l'intimité d'un spectacle, en liaison avec une structure culturelle. Parfois celle-ci délivre des billets d'entrée, comme pour tout autre spectacle; parfois elle offre le spectacle à l'hôte et à ses invités. Ça a été le cas le 14 janvier dernier au Grand Salon de la Faculté des Lettres où les étudiants et les animateurs du T.U.F.C. recevaient un spectacle programmé par le CDN parallèlement au Mariage, de Gogol (joué au théâtre municipal), le Superbaby, de Ferdinand Camon.

Quatre-vingt personnes sur les chaises, dans une disposition aléatoire qui n'est plus celle de la salle de cours, sans pour autant reconstituer ni un salon, ni une salle de théâtre. Parmi elles, un petit homme en costume foncé, d'abord inaperçu. C'est l'acteur Daniel Pouthier, du théâtre de la Chrysalide, qui, surgi du silence de l'attente, va nous faire partager les angoisses parentales des héros ordinaires du Superbaby. 


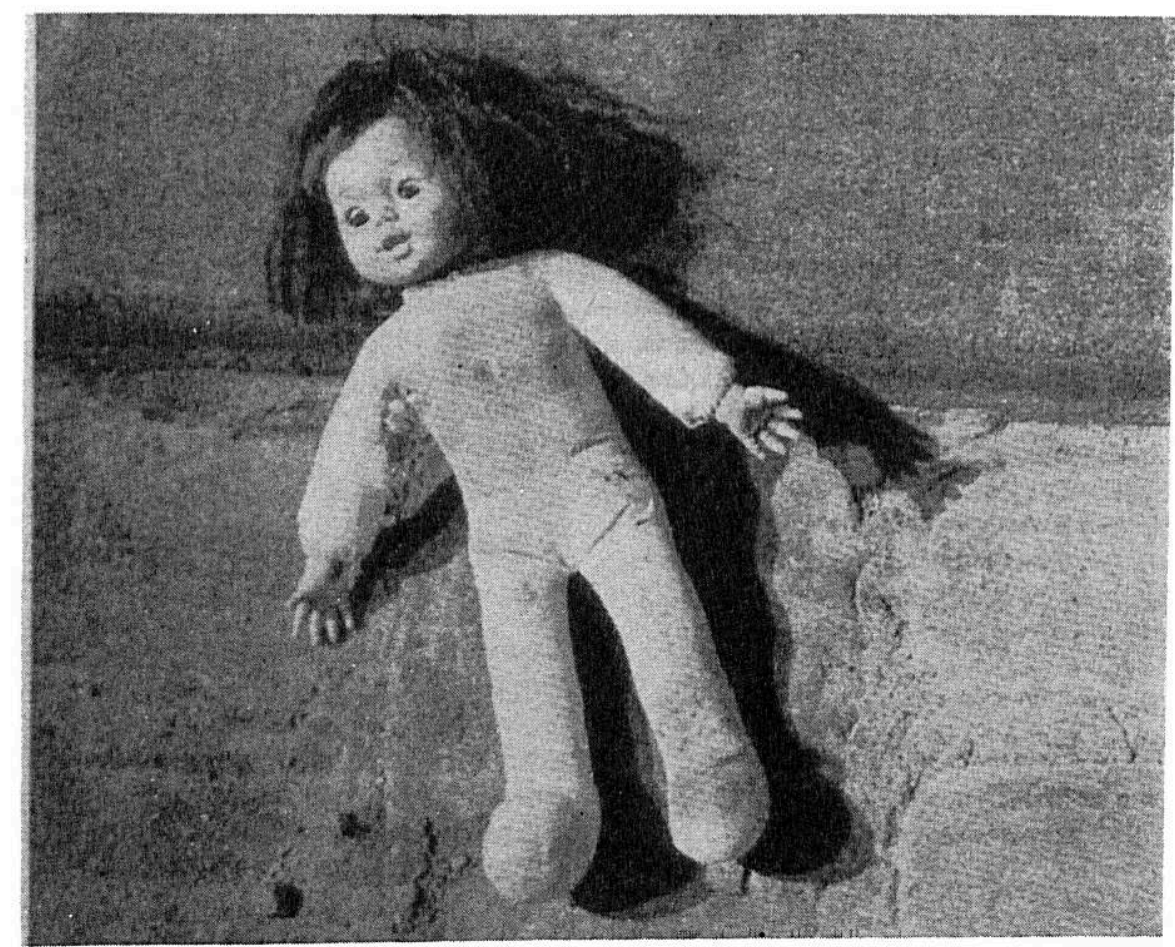

2 Camon, écrivain italien tout à fait contemporain originaire de la province de Padoue, se penche précisément avant tout sur la question des origines. Ecrire en italien quand on vient d'un village qui parle en dialecte, c'est trahir. C'est une trahison nécessaire, une trahison d'amour - donner aux habitants de ce village la dignité conférée par la littérature - néanmoins difficile à vivre : reste à travailler sur la question des origines et de l'identité par la parole, psychanalytique et littéraire. La Maladie humaine avait inspiré à Didier Bezace, au théâtre de l'Aquarium, le spectacle Les Heures blanches, mise en scène des moments « creux » où beaucoup de choses se passent dans un travail psychanalytique; la Chrysalide avait déjà monté Figure humaine, d'après le récit du même nom, récit de la «trahison » du village pour la ville.

3 Le Superbaby traite de façon savoureuse du fantasme moderne de l'enfant parfait: faute de valeurs transcendantes, les parents de la fin du vingtième siècle auraient tendance à projeter sur leur enfant, leur " produit » puisque la grande révolution bioéthique de la fin du siècle est la maîtrise quasi-totale de la fécondité humaine (mais seulement quasi, on le verra...), des valeurs identifiables de beauté physique, mais surtout de compétences supposées, intellectuelles, techniques et même artistiques, bref de réussite "dans l'œuf ». Cela avec une double fonction: armer l'enfant contre les dangers d'un monde en perpétuelle compétition, et magnifier l'ego du couple parental par la qualité du produit.

4 Evidemment, ce beau système prévoyant se fissure très vite : Camon rappelle d'entrée la terrible question de paternité - la mère, on est sûr ; le père on ne sait jamais....... -, aiguë pour tout mâle humain, et particulièrement pour le mâle méditerranéen. - Du reste, aujourd'hui, la maternité devient aussi incertaine : qui est la mère, la donneuse d'ovule ? La porteuse d'embryon ? La commanditaire de l'opération ? - Surtout le désir d'enfant est coupé de la réalité de l'enfant: gare à celui-ci s'il ne remplit pas le 
programme fantasmé.

A écouter Camon, on est touché au vif, sidéré de tant de culot, et l'on rit avec tendresse des efforts inouïs - et de l'échec - des pauvres humains à se déshumaniser. Peut-être Camon est-il là trop optimiste : la barbarie moderne est de moins en moins en échec...

5 Le sujet a priori, n'est pas particulièrement «théâtral »- bien qu'il rejoigne, sur la question de la paternité, Strindbreg (Père) et la tragédie grecque. Mais le théâtre s'y trouve : un personnage positivement banal sans être une abstraction; une situation, celle d'un homme qui doute de sa paternité et donc de sa virilité, même si celle-ci «fonctionne » bien, et donc de son humanité ; un cheminement, du contrôle décevant et destructeur jusqu'au hasard salvateur ; un langage qui, comme dans la psychanalyse, est action. Et enfin la représentation: le rapport au public, intime (le T.U.F.C. et ses invités au Grand Salon, ne réunit-il pas une " grande famille »?), est juste et nécessaire à cette histoire, intime jusqu'aux profondeurs de la cellule première. Le théâtre en appartement, d'une manière générale, radicalise le rapport théâtral, avec le maximum d'effet, de la scénographie et du jeu de l'acteur face à un public à la distance exacte où cesse la conversation - ou l'écoute d'un soliloque - et où commence le théâtre, étant entendu que cette distance est créée, non mesurable, par le jeu.

Pour mener à bien - et l'intérêt et le plaisir des spectateurs écoutant ce Superbaby justifie l'expression - ce spectacle, à côté du travail propre à l'équipe de création et à celle du CDN, les étudiants et les animateurs du T.U.F.C. ont organisé l'accueil, en bon maître de maison, installant le lieu (avec un clin d'œil charmant au thème, sous forme d'un bébé «Bambino" en porcelaine et de dragées blanches...) et organisant la convivialité autour d'un " pot », heureux moment d'échanges et de paroles sur un sujet qui tient à cœur - et plus que cela - à chacun. Une forme de collaboration à renouveler et à développer entre le CDN et le T.U.F.C. 